\title{
"Chinese renminbi, Mexican peso U.S. dollar exchange rates and their competitive positions in export markets"
}

\author{
Chu V. Nguyen \\ AUTHORS Muhammad Mahboob Ali \\ Cory Angert
}

Chu V. Nguyen, Muhammad Mahboob Ali and Cory Angert (2016). Chinese

ARTICLE INFO renminbi, Mexican peso U.S. dollar exchange rates and their competitive positions in export markets. Banks and Bank Systems, 11(1), 42-51. doi:10.21511/bbs.11(1).2016.05

DOI http://dx.doi.org/10.21511/bbs.11(1).2016.05

RELEASED ON Monday, 25 April 2016

JOURNAL "Banks and Bank Systems"

FOUNDER LLC "Consulting Publishing Company "Business Perspectives"

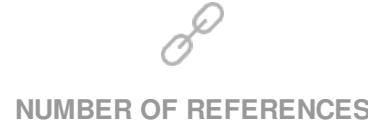

0

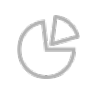

NUMBER OF FIGURES

0

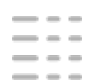

NUMBER OF TABLES

0

(C) The author(s) 2022. This publication is an open access article. 


\title{
Chu V. Nguyen (USA), Muhammad Mahboob Ali (Bangladesh), Cory Angert (USA) Chinese renminbi, Mexican peso - U.S. dollar exchange rates
and their competitive positions in export markets
}

\begin{abstract}
Since, in the NAFTA era, the Mexican economy is much more advanced in the manufacturing sector than those of other Latin American countries, Mexico competes directly with China for U.S. imports. This study empirically investigates the behavior of the Mexican peso/Chinese yuan, Mexican peso/U.S. dollar, and Chinese yuan/U.S. dollar real exchange rates to determine whether the exchange rate policies serve as contributing factors to the subpar performance of the Mexican economy. The empirical findings suggest that the Mexican, Chinese, and U.S. real exchange rates, over the sample period, prove consistent with predations of the purchasing power parity theory; therefore, exchange rate policies may not be a contributing factor to the poor performance of the Mexican economy.
\end{abstract}

Keywords: real exchange rate, competitive position, export market, renminbi, Mexican peso.

JEL Classification: C25, F3, F30, F31.

\section{Introduction}

Continuously fluctuating, oftentimes unpredictable, currency exchange rates can have a most significant impact on a wide array of economic factors. As the nations of the world grow ever more closely interlinked, the importance of understanding the influence of exchange rates on international trade becomes essential for scholars seeking to analyze the elements that materially contribute to a country's economic performance. Unfortunately, international economic and finance theories do not provide definitive guidance as to the causal relationship between exchange rate changes and output growth; the debates are usually informed by empirical analyses that often yield ambiguous results.

The 1994 signing of the North American Free Trade Agreement (NAFTA) created a new playing field for the United States of America, Canada, and Mexico. Prior to the passage of NAFTA, Mexico had employed various trade policies, including a managed flexible float regime and an exchange rate bands with managed slippage approach. Since December 22, 1994, however, the country has maintained a free float system, which emphasizes flexible exchange rates. In contrast, the Chinese government has held firmly to a competitive exchange rate method that aligns the value of the yuan with that of a basket of other currencies. Until 2005, the U.S. dollar was used as a benchmark in place of the broader basket of currencies currently employed. As a result, the nominal exchange rates of the two countries differ drastically, with Mexico's typically

(c) Chu V. Nguyen, Muhammad Mahboob Ali, Cory Angert, 2016.

Chu V. Nguyen, Associate professor of Economics and Finance and Chairman, FACIS Department, College of Business, University of Houston-Downtown, USA.

Muhammad Mahboob Ali, Professor, Department of Business Administration, and Director, Institutional Quality Assurance Cell, Daffodil International University, Dhaka, Bangladesh.

Cory Angert, Visiting Assistant Professor of Management, MMBA Department, College of Business, University of Houston-Downtown, USA. failing to remain as stable as China's exchange rate, a combination that drives away foreign direct investment (FDI), as most investors tend to eschew such uncertainty (Weisbrot et al., 2014).

As far as it may be ascertained, there exists no other analysis of the Mexican peso/Chinese yuan real exchange rate. Similarly, previous research has neither addressed Mexico's competitive bilateral export market position in regard to that of China nor has the literature investigated Mexico's ability to compete with China for U.S. imports.

At the end of 1993, Mexico was considered an exemplary model for developing countries; five years of prudent fiscal and monetary policy had dramatically lowered Mexico's budget deficit and inflation rate, and the government had privatized many enterprises that were formerly state-owned. However, this fiscal prosperity dramatically altered with the 1994 passage of NAFTA, especially when compared to China's economy. In regard to economic performance, the Chinese economy has performed very well post 1994, while the Mexican economy has faltered, even as compared to its developmentalist past, which contrasts with the economies of its Latin American neighbors. In December 1994, less than one year after the implementation of NAFTA, investors began liquidating their pesodenominated assets, causing the value of the Mexican peso to plunge 50.0 percent against the U.S. dollar. Mexico was forced to borrow from the International Monetary Fund (IMF) and the United States in order to weather the financial crisis. In 1995, inflation in Mexico soared to 50.0 percent, and real GDP fell by 4.0 percent (Neely, 1996).

The persistently poor performance of the Mexican economy has spawned research in pursuit of plausible explanations (Weisbrot et al., 2014; Weisbrot and Ray, 2011; Weisbrot et al., 2004; Villarreal, 2010; Neely, 1996; Blavy and Juvenal, 2008; and Kose et al., 2004). Theoretically, for a small and 
open economy such as Mexico's, one or a combination of the following factors may be the cause(s) for the Mexican economy's poor performance: policy measures that affect international trade flows (i.e., protective tariffs); quantity restrictions, special licenses and permits; or exogenous factors such as business cycles, international competition, and exchange rate policy.

In regard to the aforementioned, as far as it may be ascertained, there is no other analysis on the relative renminbi vs. U.S. dollar, Mexican peso vs. U.S. dollar, and Mexican peso vs. renminbi values to assess their competitive positions in bilateral export markets and, to some degree, Mexico's ability to compete with China for U.S. imports. Therefore, the objective of this study is to empirically investigate the behavior of the peso/yuan, peso/dollar and yuan/dollar real exchange rates to evaluate the Mexican and Chinese competitive positions in the NAFTA era.

The remainder of this investigation is organized as follows: Section 1 reviews the literature concerning the impact of exchange rate changes on the economy; Section 2 introduces the framework for this empirical investigation; Section 3 describes the data and variables; Section 4 summarizes the methodology; Section 5 reports the results; Section 6 provides the discussion, and the Final Section provides some concluding remarks.

\section{Review of the literature}

Research has found evidence supporting the assertion that undervalued exchange rates prove beneficial to developing countries; because, unlike in the case of overvalued exchange rates, this imbalance often results in the stimulation of economic activity and increased employment (Rodrick, 2008; Bhalla, 2012). One possible explanation for this finding is that an undervalued exchange rate encourages a shift in productive resources toward industries heavily focused on imports and exports. These industries typically exhibit productivity rates higher than those associated with other industries (Cottani et al., 1990) and economies of scale, learning by doing, and knowledge spillovers larger than those attributed to industries less heavily-focused on importing/exporting (Rodrick, 2008). The swing can accelerate a country's development and make it more competitive internationally (Bhalla, 2012). While these positive effects make undervaluation a seemingly attractive prospect for developing nations, some research has discovered that undervaluation can also result in undesirable consequences.

Additionally, it is entirely possible that exchange rate devaluations can cause a reduction in output, known as contractionary devaluation, a phenome- non for which Mexico has been explicitly cited as an example (Dhasmana, 2015). Furthermore, purchasing power parity (PPP) theory warns that currency devaluation is typically followed by high inflation rates; a decline in national income (which could foment discontent and lead to social unrest); and a rise in cyclical instability, personal bankruptcies, and speculation in the real estate and equity markets. Also, the scale and scope of negative impacts are influenced by the culture and degree of economic and political freedom of the country.

One of the major issues encompassing the exchange rate literature has been the choice of exchange rate regime. This topic has been a subject of ongoing debate in international economics (Priyo, 2009; Bailliu et al., 2002). The debate has spawned a number of empirical studies as to the existence of the relationship between economic growth and the choice of exchange rate regime. Some of the empirical results show that no relationship exists between exchange rate regime and economic growth (Ghosh et al., 1997; the IMF study, 1997), while others have found evidence linking the two (Bailliu et al., 2001; Calvo and Reinhart, 2000; Levy Yeyati and Sturzenegger, 1999; Levy Yeyati and Sturzenegger, 2001). However, none of these studies seems to be able to answer which regime is the best in terms of achieving fast, sustainable economic growth. To this end, it is true that the choice of the regime and its success depend on individual countries and their own economic considerations and environments (Dehejia, 2003).

Moreover, while the advantages of freely floating regimes are well known, it is still debated whether this type of regime is suitable for less developed countries. The problem of destabilizing speculation and consequent excessive exchange rate volatility appears to be exacerbated in developing countries, making a floating regime especially unviable/unsuitable, particularly in the absence of a resilient and developed financial system (Hossain and Ahmed, 2009; Grenville and Gruen, 1999). After the Asian and Latin American crises in the 1990s, there has been a growing tendency among countries to adopt a corner regime - either a fixed or a floating regime. However, many studies document that the way developing countries float is not consistent with the characteristics of clean floats (Hausmann et al., 2001; Hernandez and Montiel, 2003).

\section{Framework for empirical investigation}

International finance literature theory articulates that fluctuations in a home country's inflation alter the inflation rate differential between the home country and its trading partners. Under relative purchasing power parity (PPP), the differential infla- 
tion rates in the two economies must be exactly offset by changes in the respective nominal exchange rates so that the two countries' competitive positions will be unaffected (Eun and Resnick, 2015). In this context, the real exchange rate sheds light on the home country's competitive position relative to that of the trading partner. The real exchange rate is denoted by $q$, and is expressed as:

$$
q=\frac{1+\pi_{h c}}{\left(1+\varepsilon_{h c, t p}\right)\left(1+\pi_{t p}\right)},
$$

where $\pi_{h c}$ is the home country's inflation rate, $h c=$ home country (Mexico in this study); $\pi_{t p}$ is the inflation rate of its trading partner $t p$, and $\left(1+\varepsilon_{h c, t p}\right)$ is the ratio of the home country's currency to the currency of its trading partner $t p$ exchange rate to this exchange rate in the previous period.

PPP theory states that the real exchange rate is unitary, meaning that, in the above equation, $q$ would be equal to 1 . Ceteris paribus, an increase in the trading partner's currency would result in a decrease to the real exchange rate, which would enhance the competitive position of the home country relative to that of its trading partner. Similarly, ceteris paribus, $q$ would increase beyond unity should the inflation rate of the home country be higher than the inflation rate of its trading partner, resulting in a weaker competitive position for the home country. In this case, to prevent a rise in the real exchange rate, the home country's currency price of the trading partner's currency must rise to reflect the inflation differential.

\section{Data and variables}

In order to calculate $q$, the real exchange rate presented in equation (1), for Mexico and China, this study used monthly time series data comparing nominal exchange rates for the Chinese renminbi and the U.S. dollar, exchange rates for the Mexican peso and the U.S. dollar, and consumer price indices for China, Mexico, and the United States. The data for all time series are from the Board of Governors of the Federal Reserve System and the FRED of the Federal Reserve Bank of St. Louis and cover the January 1994-July 2015 period.

\section{Methodology}

Since a certain degree of noise is inherent in any type of monthly data, and because inertia is likely to prevent most businesses from immediately altering strategy and operations based on monthly exchange rate fluctuations, the above calculated $q$, using monthly data, should be expected to be different from unity. The question arises as to whether the calculated real exchange rate, $q$, is statistically different from unity at any conventional levels of significance. To address the excessive noise in the monthly data and the rigidity in business operations, this study will calculate and analyze the 12-month, 24-month, and 36-month moving averages of $q$ in addition to its monthly values.

To statistically test whether the calculated real exchange rate, $q$, is statistically different from unity at conventional levels of significance, this study calculates the \pm 2 standard errors of the relative real exchange rate $q$ to determine whether the band of \pm 2 standard errors for any given $q$ contains unity, i.e., the line $q=1$.

Additionally, under the normality assumption, which would be tested using Doornik and Hansen's (1994) test statistic (if a series $q$ is normally distributed, then, any of its moving average is also normally distributed), if $\sigma_{q}$ and $\mu_{q}$ are, respectively, the standard deviation and the mean of a calculated time series for a given $q$, then, probability theory states:

$$
\operatorname{Pr}\left(\mu_{q}-2 \sigma_{q} \leq \mu_{q} \leq \mu_{q}+2 \sigma_{q}\right)=95.4 \% .
$$

As described by equation (1), under PPP, the real exchange rate is expected to be unitary, $q=1$. Therefore, if a band of \pm 2 standard errors for any of these calculated series $q$ contains unity, the probability for that series to be statistically equal to 1 is 95.4 percent and to be different from one is 4.5 percent.

Statistically, the aforementioned can be restated as: if the band of the \pm 2 standard errors of any of these series $q$ contains unity, the hypothesis that the series $q$ is different from one should be rejected at the 5 percent level of significance.

\section{Empirical results}

5.1. Relative inflation rates. Figures 1,2 , and 3 display the inflation rates of China relative to the United States, of Mexico relative to the United States, and of Mexico relative to China, respectively. These graphs evidence three important conclusions. First, as depicted in Figure 1, inflation was lower in China than in the U.S. during the period between 1994 and 2006; but, outside of a steep decline at the beginning of 2015, Chinese inflation was greater than that of the United States from 2006 until 2015, the last studied year. Second, Figure 2 shows that Mexico's rate of inflation is higher than the U.S.'s inflation rate but that Mexico's inflation rate achieved and maintained stability beginning in 1999. Finally, it is apparent in Figure 3 that Mexico's inflation rate far exceeded that of China for most of the 1990s and, other than a drastic 2015 anomaly, remained relatively stable during most of the years included in this study. 


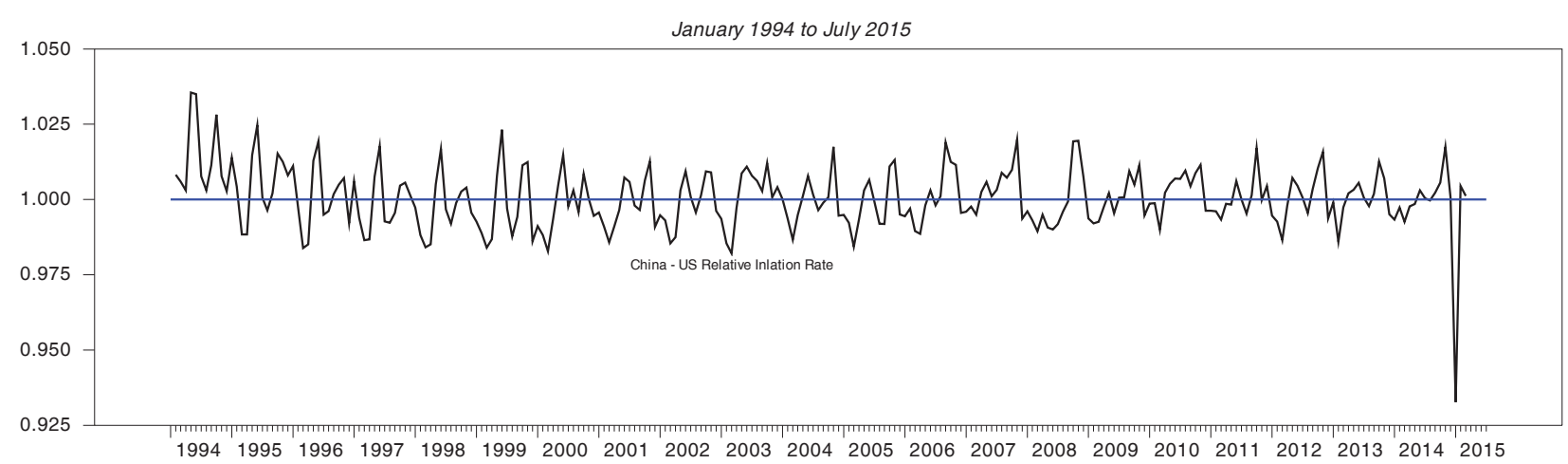

Fig. 1. China's inflation rate relative to U.S.'s inflation rate

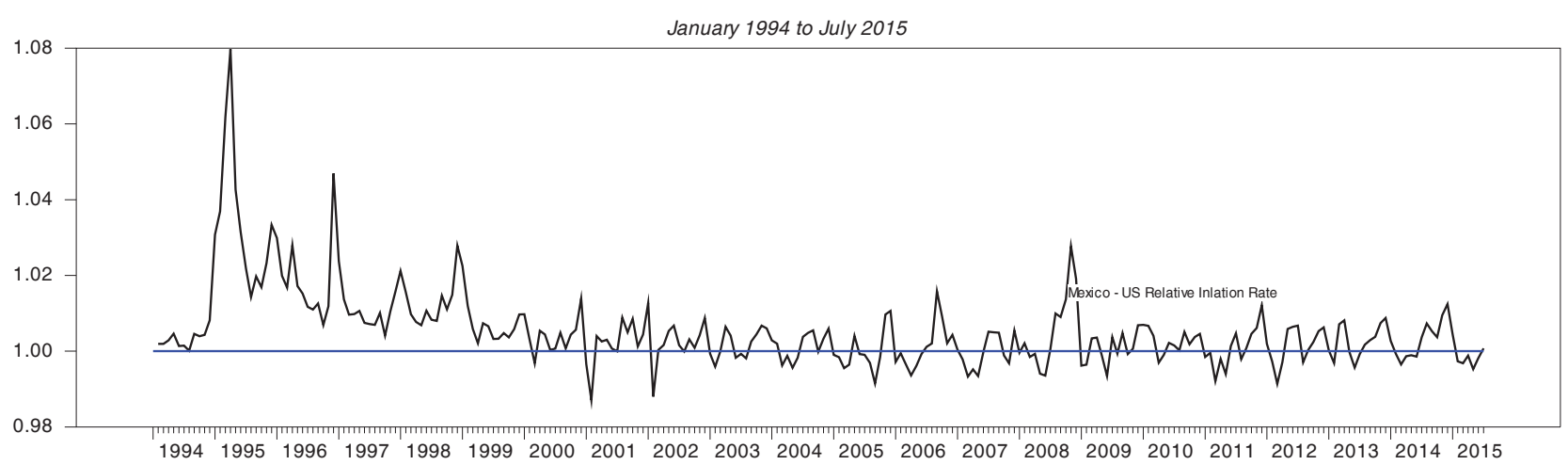

Fig. 2. Mexico's inflation rate relative to U.S.' s inflation rate

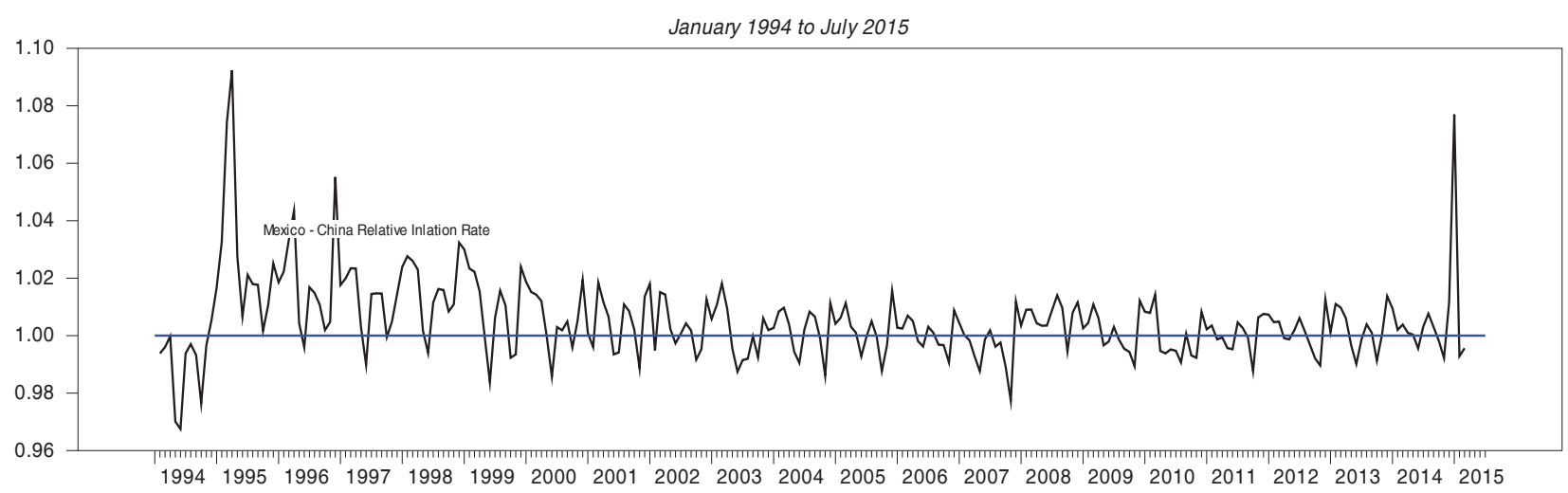

Fig. 3. Mexico's inflation rate relative to China's inflation rate

5.2. Real exchange rates. Figures 4,5 , and 6 (see below), respectively, illustrate the calculated relative renminbi-dollar, peso-dollar, and peso-renminbi real exchange rates between 1994 and 2015. Although the calculated results naturally differ from 1 , further investigation is necessary to determine whether either Mexico's or China's relative real exchange rates significantly differ from unity or include unity within any \pm 2 standard error bands.

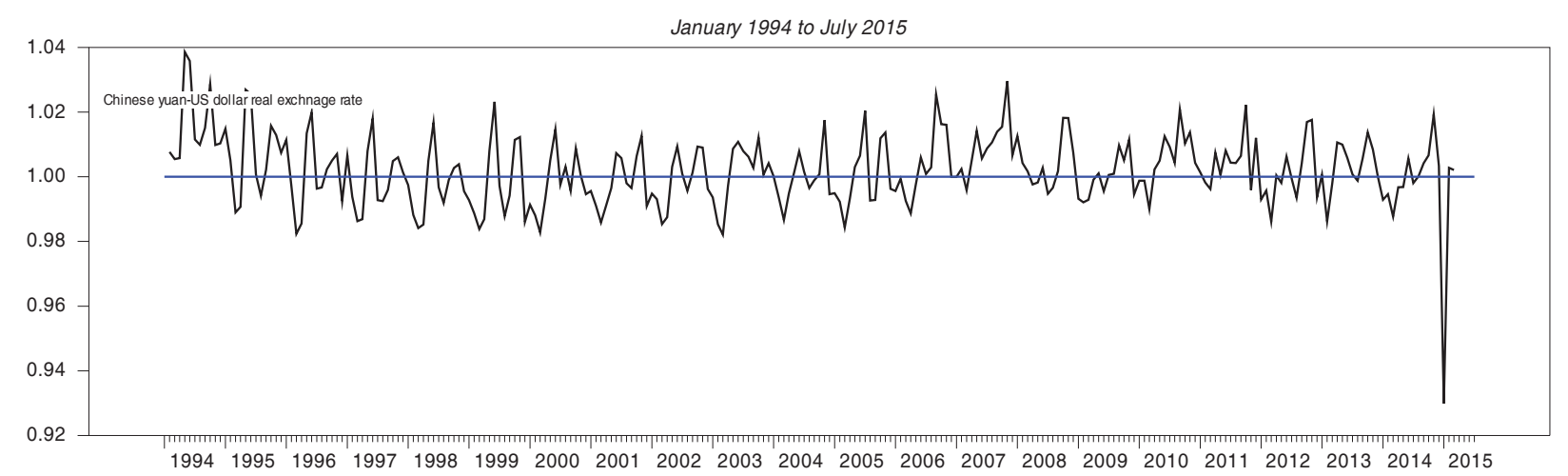

Fig. 4. Chinese yuan-U.S. dollar real exchange rate 


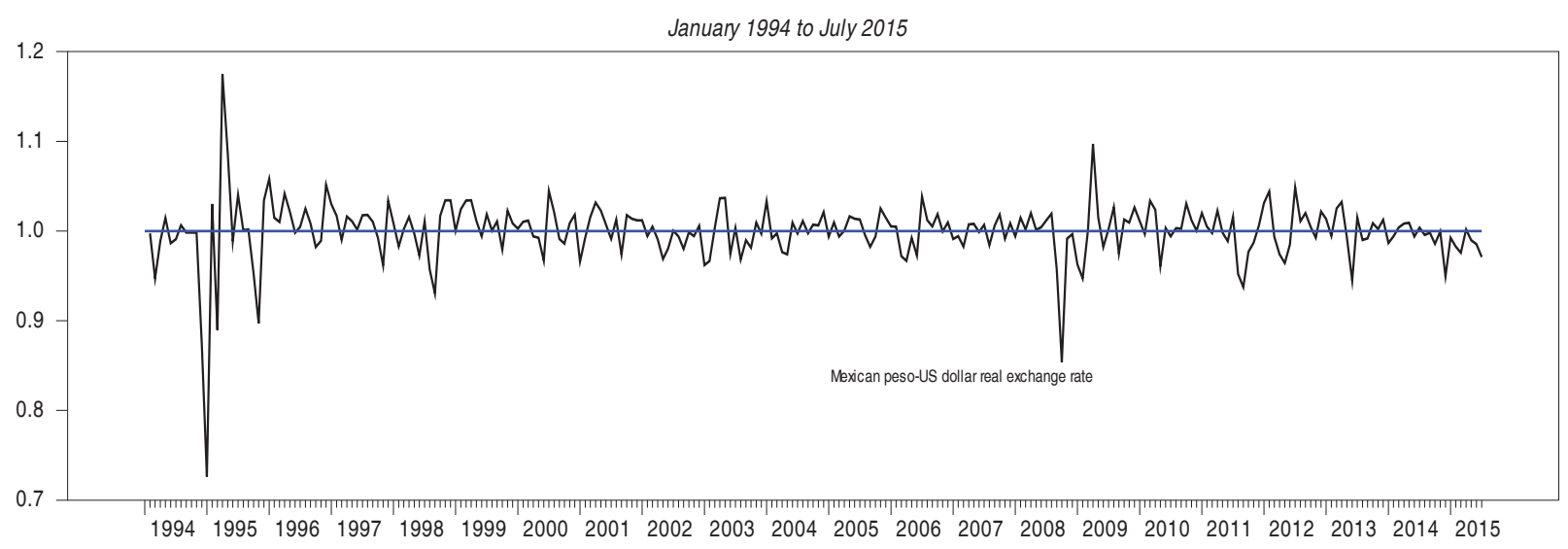

Fig. 5. Mexican peso-U.S. dollar real exchange rate

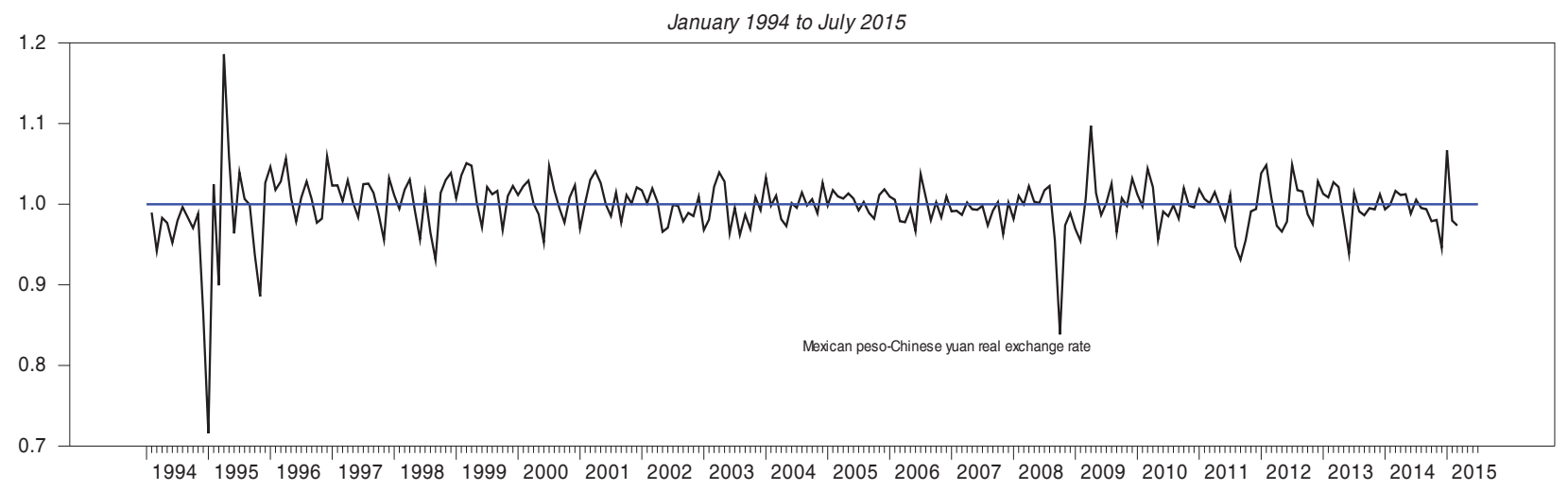

Fig. 6. Mexican peso-Chinese yuan real exchange rate

Before testing for normality, this investigation utilizes the Kwiatkowski-Phillips-Schmidt-Shin test to assess the stationarity of the three calculated real exchange rate series. The testing result reveals that, with 259 observations, and as compared to the 1 percent level of significance of 0.7390, the calculated Kwiatkowski-Phillips-Schmidt-Shin test statistics for the renminbi vs. the U.S. dollar, the Mexican peso vs. the U.S. dollar, and the Mexican peso vs. the renminbi are $0.07077,0.07074$ and 0.079277 , respectively. These results suggest that all three calculated relative real exchange rates are stationary.

As a result of anomalous political, economic, and other types of disruptions that often arise within any society, our data set contains multiple outliers. Additionally, it is well known that all tests for normality are sensitive to outliers in the series being tested, and the usual method to remove the impact of outliers is to dummy them out. In fact, Doornik and Hansen's (1994) test statistic rejects the null hypothesis of normality for the entire calculated real exchange rate series for China, Mexico, and the U.S.

To correct the impact of the outliers' causing rejection of a normality assumption, this study uses the recursive Chow test to identify outliers in these real exchange rate series and dummies them out. For the relative renminbi vs. U.S. dollar exchange rate, the recursive Chow test identified the outliers that occurred in May, June, and October 1994; November
2007; and January 2015. As to the relative Mexican peso vs. U.S. dollar exchange rate, the outliers are found to be in March and December 1994; January, March, April, May, October, and December 1995; November and December 1996; September 1998; October 2008; February and April 2009; August 2011; June 2011; and December 2014. Finally, for the relative Mexican peso vs. renminbi exchange rate, the outliers are identified in December 1994; January, March, April, and November 1995; October 2008; and April 2009. After the aforementioned outliers were dummied out of the corresponding time series data, Doornik and Hansen's (1994) test statistic, which has a Chi-square distribution with two degrees of freedom, was used to test the null hypotheses that these series are normally distributed. The test statistics for the renminbi vs. the U.S. dollar, the Mexican peso vs. the U.S. dollar, and the Mexican peso vs. the renminbi are, respectively, 2.9866 with its $p$-value being 0.2246 , 1.2234 with its $p$-value being 0.5424 , and 1.5823 with its $p$-value of 0.4538 . Based on their $p$-values, the null hypotheses should not be rejected at any conventional levels of significance. Failure to reject the null hypothesis of normality indicates that the real exchange rates series for China, Mexico, and the U.S. are, in fact, normally distributed.

Given that the relative real exchange rate is normally distributed and that there is some degree of rigidity in business operations, it is informative to determine whether the band of \pm 2 standard errors of any of these 
moving averages series of the real exchange rate $q$ for China, Mexico, and the U.S. contains unity. Since, if the band of \pm 2 standard errors of a moving average of a given series contains unity, the hypothesis that the series in question is different from one should be rejected at the 5 percent level of significance.

5.3. Moving averages. The 36-, 24-, and 12-month moving averages calculated for the renminbi-dollar real exchange rate $(q)$ and the associated \pm 2 standard errors bands are represented in Figures 7, 8, and 9. In accordance with PPP theory, all three moving averages varied in relation to changes in relative inflation rates. It should be noted that, after 2007, the line of $q=$ 1 predominantly falls below each of the \pm 2 standard errors bands, which indicates an overvaluation of the renminbi-dollar real exchange rate.

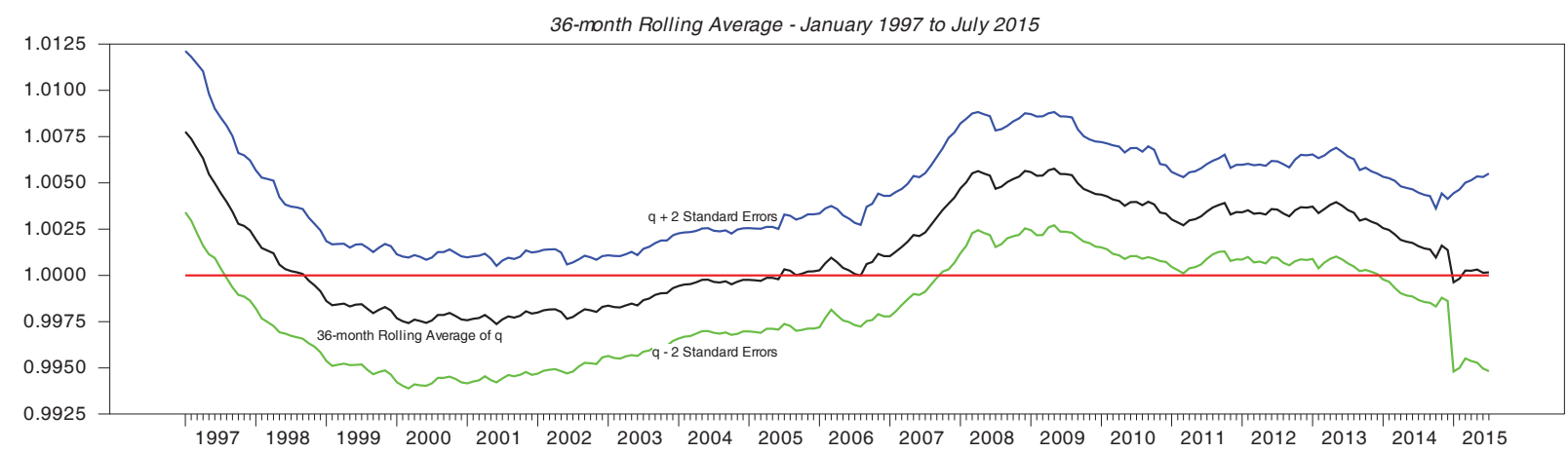

Fig. 7. Mexican peso-Chinese yuan real exchange rate

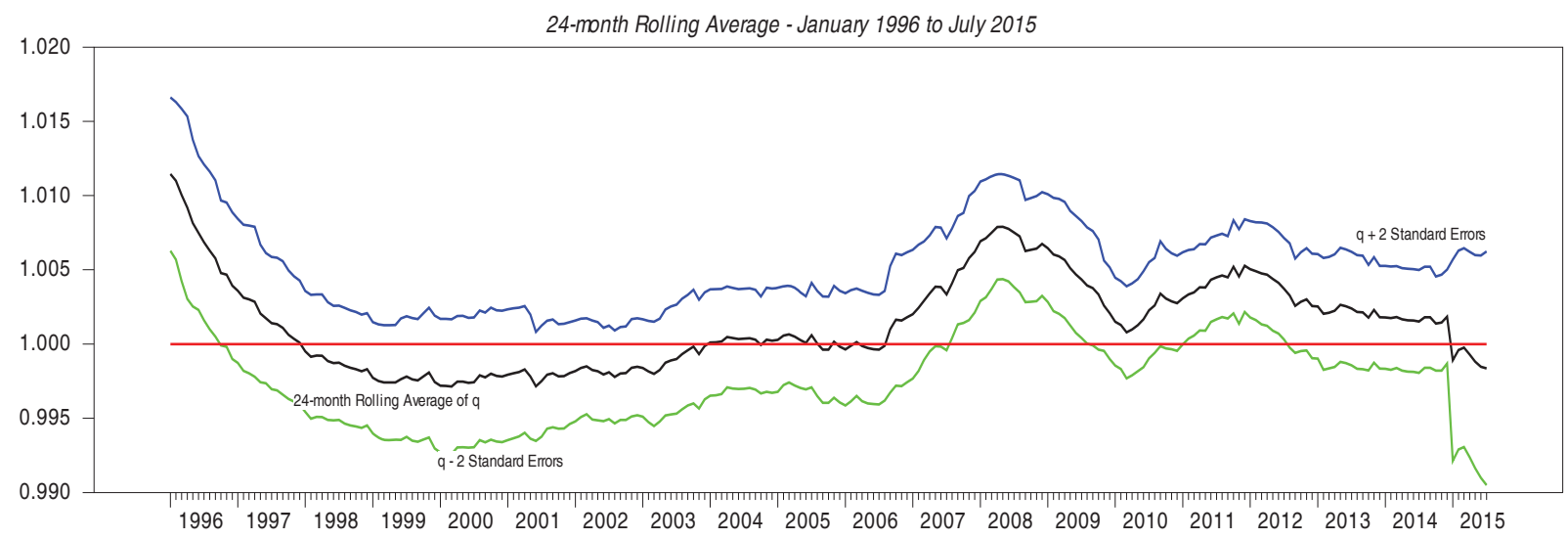

Fig. 8. Chinese yuan-U.S. dollar real exchange rate

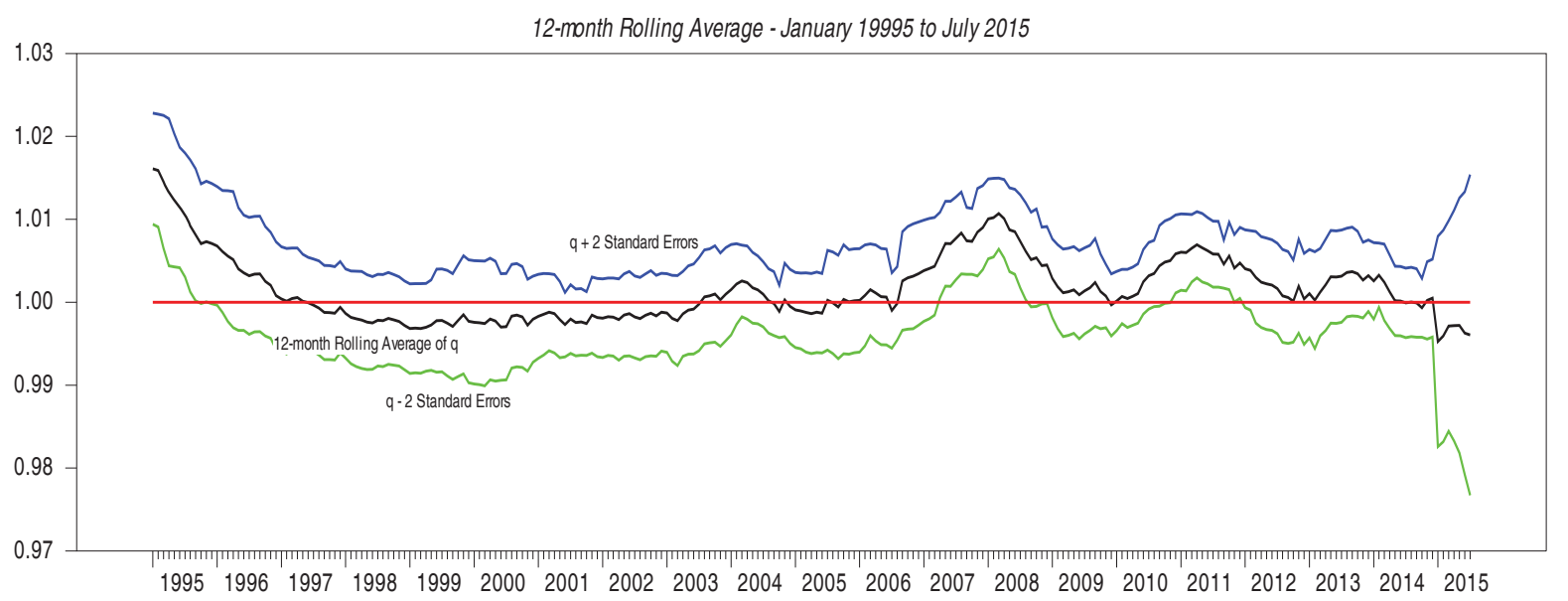

Fig. 9. Chinese yuan-U.S. dollar real exchange rate

5.4. Mexican peso-U.S. dollar. The 36-, 24-, and 12-month moving averages calculated for the peso-dollar real exchange rate $(q)$ and the associated \pm 2 standard errors bands are represented in Figures 10, 11, and 12. Other than during selected brief periods between 1998 and 2001, the $q$ $=1$ line remains inside the bands; and, in line with the PPP theory precept that inflation rate 
imbalances must be counterbalanced with commensurate exchange rate variations, each of the moving averages fluctuates rather drastically around this line.

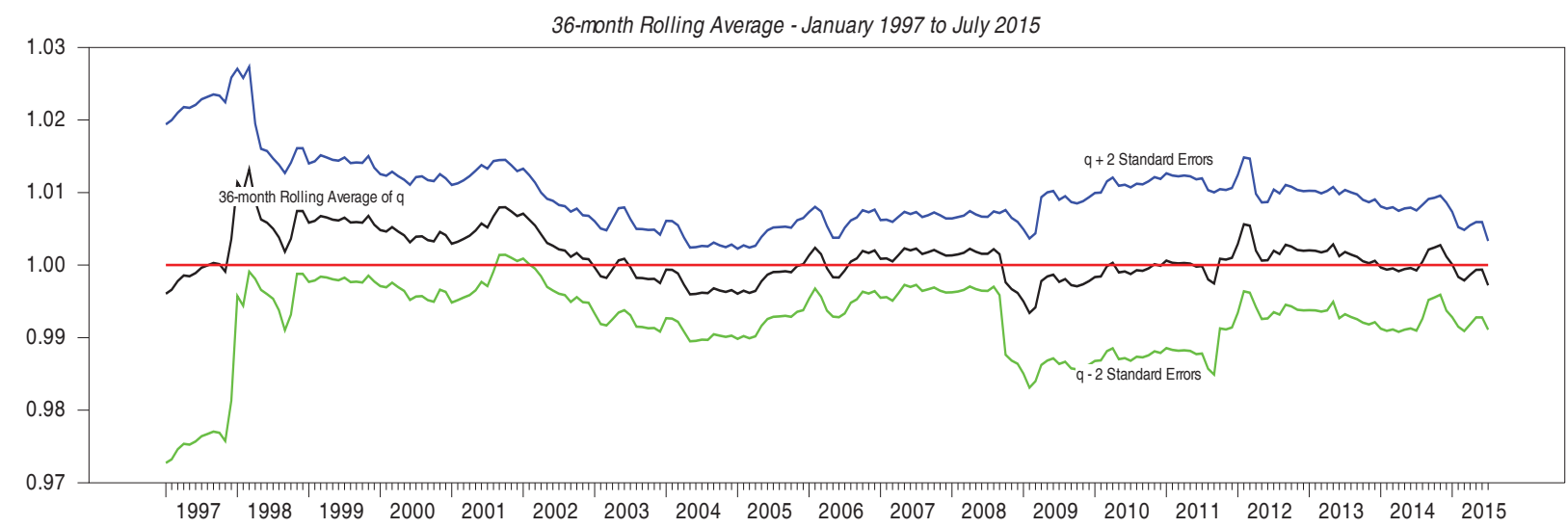

Fig. 10. Mexican peso-U.S. dollar real exchange rate

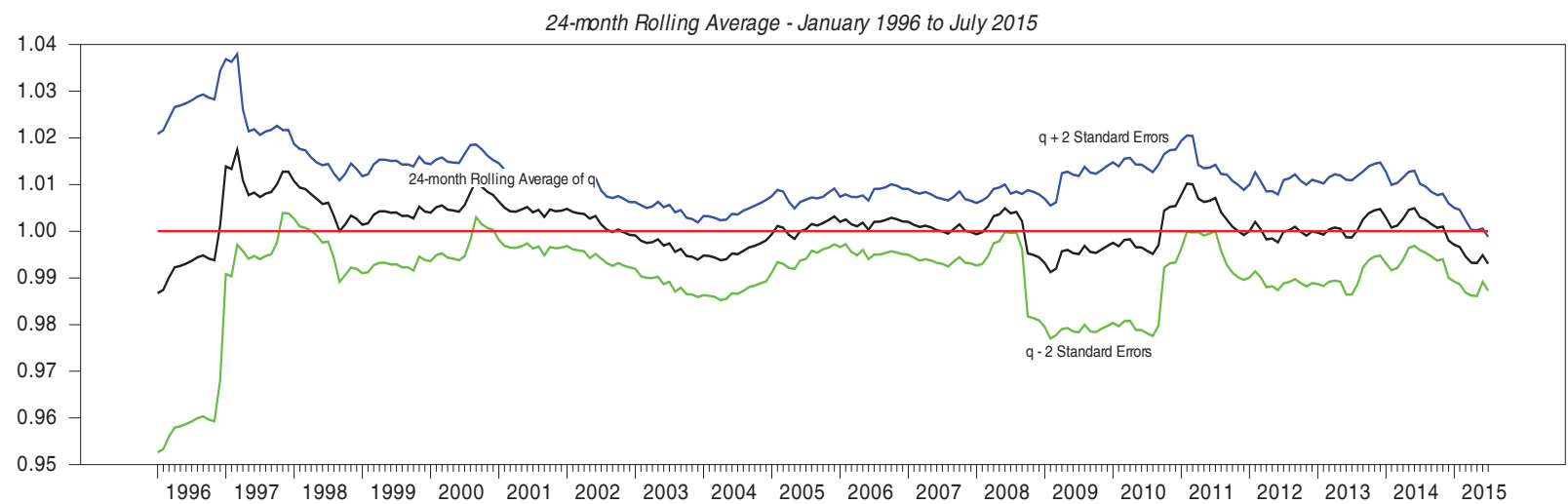

Fig. 11. Mexican peso-U.S. dollar real exchange rate

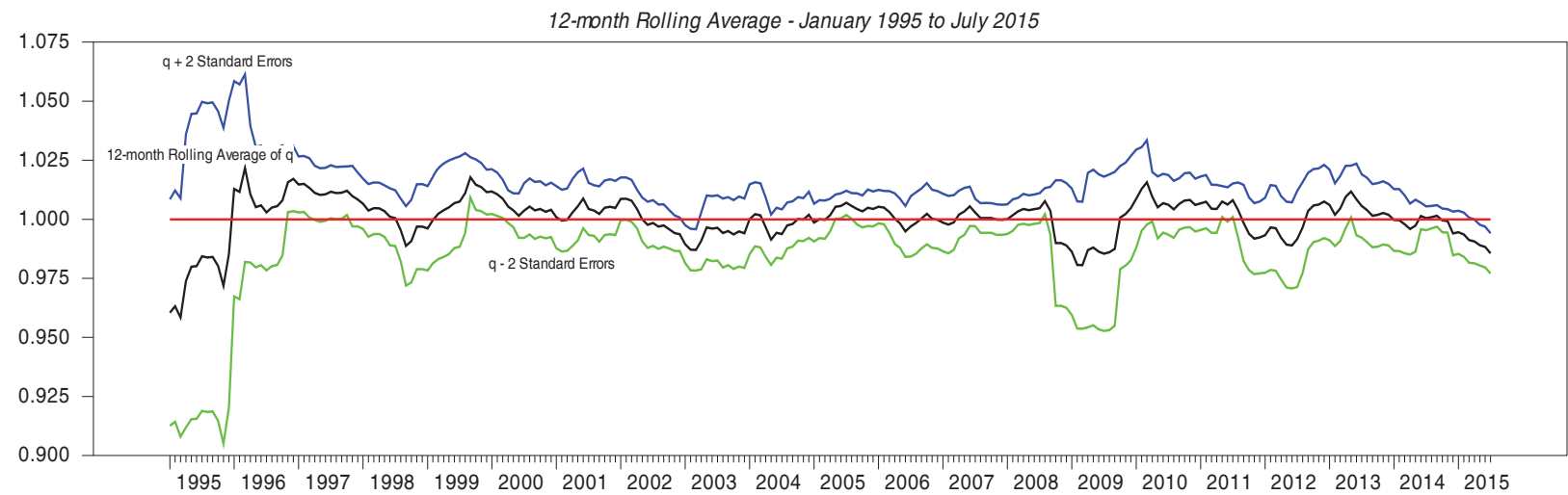

Fig. 12. Mexican peso-U.S. dollar real exchange rate

5.5. Mexican peso-Chinese yuan. The 36-, 24-, and 12-month moving averages calculated for the peso-renminbi real exchange rate $(q)$ and the associated \pm 2 standard errors bands are represented in Figures 13, 14, and 15. As was the case in the peso-dollar relationship, besides selected brief periods between 1998 and 2001, the $q=1$ line remains inside the bands, and each of the moving averages fluctuates quite radically around this line. 


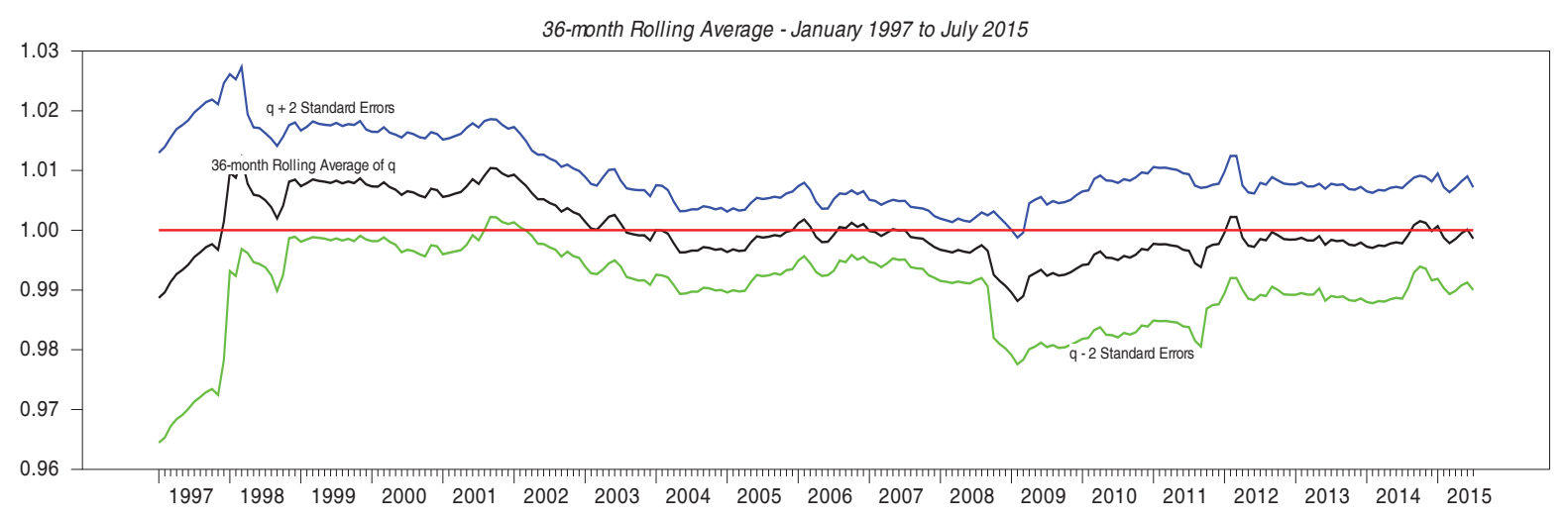

Fig. 13. Mexican peso-Chinese yuan real exchange rate

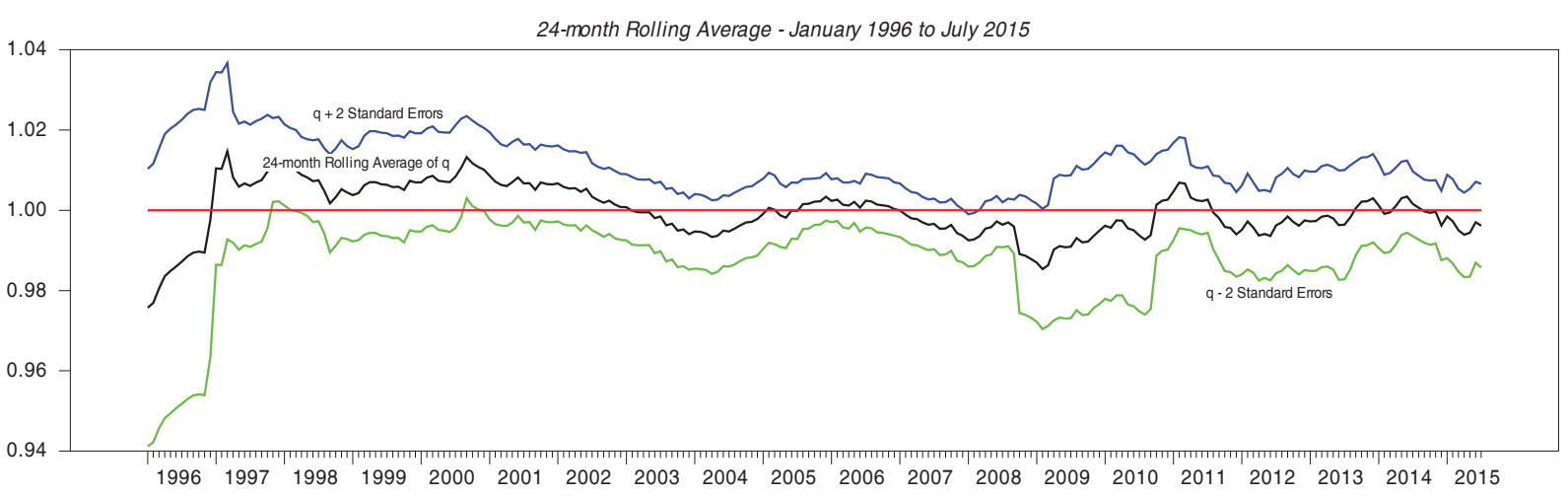

Fig. 14. Mexican peso-Chinese yuan real exchange rate

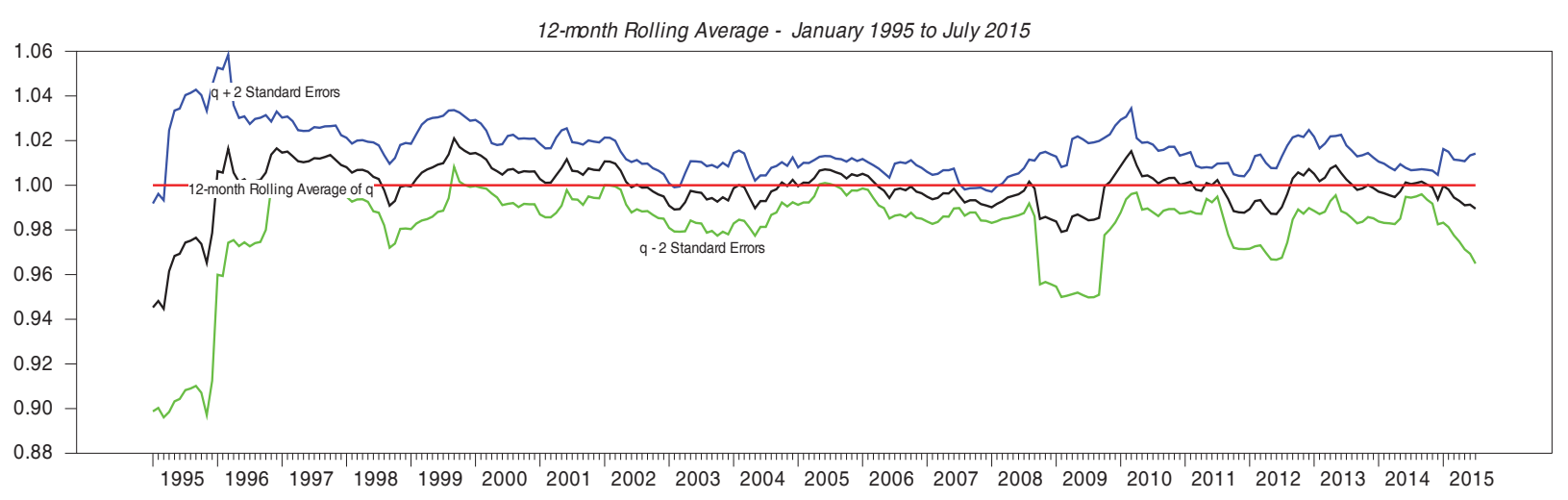

Fig. 15. Mexican peso-Chinese yuan real exchange rate

\section{Discussion}

The existence of outliers in a data set is a common occurrence that must be addressed if one wishes to attain results that are not skewed by these inconsistent anomalies. We believe that most irregularities exhibited by the data included in this study can be accounted for by a combination of the nature of each country's economy (China's is in the midst of transition, while Mexico's continues to develop) and atypical political, economic, and other disturbances. After applying a recursive Chow test to dummy out any outliers, the calculated Doornik and Hansen's (1994) test statistic confirmed that all remaining data were normally distributed. The results obtained suggest that, beyond brief isolated incidents during the late 1990s and early 2000s, each of the real exchange rate moving averages was consistent with predictions by PPP, meaning that one could assume that each of the studied nations' competitive trade positions were maintained in the NAFTA era.

\section{Concluding remarks}

International finance literature theory articulates that changes in a country's exchange rate impact its Gross Domestic Product and unemployment. Unfortunately, international economic and finance theory does not provide definitive guidance as to the causal relationship between exchange rate changes and output growth; the debates are usually informed by empirical analyses that often yield ambiguous results. Moreover, fluctuations in a home country's inflation alter the inflation rate differential between the home country and its trading partners. Under relative purchasing power parity, the differential inflation rates in the two 
economies must be exactly offset by changes in the respective nominal exchange rates so that the two countries' competitive positions will remain unaffected.

By employing monthly exchange rate data drawn from the period January 1994 through April 2015, this investigation compared China's and Mexico's competitive positions as they relate to trade with the United States and found that both countries' inflation rates were higher than that of the United States and that Mexican inflation rates were, in general, above Chinese inflation rates. All real exchange rate moving averages renminbi-dollar, peso-dollar, and peso-renminbi were, throughout the course of the studied sample period, consistent with PPP predictions. The results presented fall in line with PPP theory principles and imply that Mexico's lacking economic performance relative to its own preNAFTA performance and to neighboring nations' current performance is most likely not directly attributable to its exchange rate policies.

\section{References}

1. Bailliu, J., Lafrance, R. and Perrault, J.F. (2002). Does Exchange Rate Policy Matter for Growth? Bank of Canada Working Paper (June, 2002), pp. 17.

2. Exchange Rate Regimes and Economic Growth in Emerging Markets. Revisiting the Case for Flexible Exchange Rates. (2001). Proceedings of a conference held by the Bank of Canada, November 2000. Ottawa: Bank of Canada. pp. 317-345.

3. Bhalla, S. (2012). Devaluing to prosperity: Misaligned currencies and their growth consequences, Washington DC, DC, Peterson Institute for International Economics.

4. Blavy, R. and Juvenal, L. (2008). Mexico's Integration into NAFTA Markets: A View from Sectoral Real Exchange Rates and Transaction costs. IMF Working paper WP/08/123, IMF, Washing, D.C.

5. Calvo, G. and Reinhart, C. (2000). Fear of Floating. Available at: http://www.puaf.umd.edu/papers/ reinhart/fearrev.pdf.

6. Cottani, J.A., Cavallo, D.F. and Shahbaz Khan, M. (1990). Real exchange rate behavior and economic performance in LDCs, Economic Development and Cultural Change, 39 (1), pp. 61-76.

7. Dhasmana, A. (2015). Transmission of Real Exchange Rate to the Manufacturing Sector: Role of Financial Access. Working paper No. 476, Indian Institute of Management. India.

8. Dehejia, V.H. (2003). The Choice of Monetary/Exchange Rate Regimes: Concepts and Arguments. This paper is based upon a talk given at the Department of Economics, Comenius University, Bratislava, Slovakia, (October 31, 2003).

9. Doornik, J.A. and Hansen, H. (1994). A Practical Test for Univariate and Multivariate normality. Discussion Paper, Nuffield College.

10. Easterly, W. (2005). National policies and economic growth. In Philippe Aghion and Steven Durlauf, editors, Handbook of Economic Growth 1, Elsevier.

11. Eun, C.S. and Resnick, B.B. (2015). International Financial Management, 7th Edition. McGraw-Hill/Irwin, Boston, USA.

12. Ghosh, A.R., Gulde, A.M., Ostry, J.D. and Wolf, H.C. (1997). Does the Nominal Exchange Rate Regime Matter? National Bureau of Economic Research. Working Paper No. W5874.

13. Grenville, S. and Gruen, D. (1999). Capital flows and exchange rates, D. Gruen and L. Gower (eds.), Capital flows and the International Financial System Sydney: Reserve Bank of Australia.

14. IMF. (2013a). World Economic Outlook, October 2013. Online database. Available at: http://www.imf.org/ external/pubs/ft/weo/2013/02/weodata/index.aspx.

15. Mexico: Staff Report for the 2013 Article IV Consultation. IMF Country Report No. 13/334. Available at: http://www.imf.org/external/pubs/cat/longres.aspx?sk = 41070.0.

16. Exchange Rate Arrangements and Economic Performance in Developing Countries. (1997). World Economic Outlook, October, Chapter 4. Washington, D.C. International Monetary Fund (1997).

17. Hossain, M. and Ahmed, M. (2009). Exchange Rate Policy under Floating Regime in Bangladesh: an Assessment and Strategic Policy Options. The Bangladesh Institute of Development Studies, Working Paper Series, Working Paper No. 2.

18. Hausmann, R., Panizza, Ugo, P. and Stein, E. (2001). Why do countries float the way they float? Journal of Development Economics, Vol. 66, pp. 387-414.

19. Hernandez, L. and Montiel, P. (2003). Post-Crisis Exchange Rate Policy in Five Asian Countries: Filling in the Hollow Middle? Journal of the Japanese and International Economies, 17 (3), pp. 336-369.

20. Kose, M.A., Meredith, G.M. and Towe, C.M. (2004). How Has NAFTA Affect the Mexican Economy? Review and Evidence. IMF Working paper WP/08/123, IMF, Washing, D.C.

21. Levy Yeyati, E.L. and Sturzenegger, F. (1999). Classifying Exchange Rate Regimes: Deeds vs. Words. Available at: http://www.utdt.edu/ ely/Regimes_final.pdf.

22. Levy Yeyati, E.L. and Sturzenegger, F. (2001). To Float or to Trail: Evidence on the Impact of Exchange Rate Regimes. Available at: http://www.utdt.edu/ ely/growth_final.PDF.

23. Neely, C.J. (1996). The Giant Sucking Sound: Did NAFTA devour the Mexican Peso? Review, Federal Reserve Bank of St. Luis, July/August 1996. 
24. Priyo, A.K.K. (2009). Impact of the Exchange Rate Regime Change on the Value of Bangladesh Currency, Social Science Review (Faculty of Social Science, University of Dhaka), 26 (1) (June 2009), pp. 185-214.

25. Rodrik, D. (2008). The Real Exchange Rate and Economic Growth, Brookings Papers on Economic Activity, 2 , pp. 365-412.

26. Villarreal, A.M. (2010). NAFTA and the Mexican Economy, CRS Report for Congress: Prepared for Members and Committee of Congress. Congressional Research Service.

27. Weisbrot, M., Lefebvre, S., and Sammut, J. (2014). Did NAFTA Help Mexico? An Assessment after 20 Years. Center for Economic and Policy Research. Washington DC.

28. Weisbrot, M. and Ray, R. (2011). The Scorecard on Development, 1960-2010: Closing the Gap? Center for Economic and Policy Research, Washington, DC. April. Available at: http://www.cepr.net/index.php/publications/ reports/the-scorecard-on-development-1960-2010-closing-the-gap.

29. Weisbrot, M., Rosnick, D. and Baker, D. (2004). Getting Mexico to Grow with NAFTA: The World Bank's Analysis. Center for Economic and Policy Research, Washington, DC. October. Available at: http://www.cepr.net/index.php/publications/reports/getting-mexico-to-grow-with-nafta-the-world-banks-analysis. 